\title{
A chiral lactate reporter based on total and circularly polarized $\mathrm{Tb}$ (III) luminescence
}

Marco Leonzio, ${ }^{[1]}$ Andrea Melchior, ${ }^{*[2]}$ Georgina Faura, ${ }^{[2]}$ Marilena Tolazzi, ${ }^{[2]}$ Marco Bettinelli, ${ }^{[1]}$ Francesco Zinna, ${ }^{[3] \dagger}$ Lorenzo Arrico, ${ }^{[3]}$ Lorenzo Di Bari* ${ }^{[3]}$ and Fabio Piccinelli*[1]

${ }^{1}$ Luminescent Materials Laboratory, DB, Università di Verona, and INSTM, UdR Verona, Strada Le Grazie 15, 37134 Verona, Italy

${ }^{2}$ Dipartimento Politecnico di Ingegneria e Architettura, Laboratorio di Tecnologie Chimiche, Università di Udine, via Cotonificio 108, 33100 Udine, Italy

${ }^{3}$ Dipartimento di Chimica e Chimica Industriale, via Moruzzi 13, 56124 Pisa, Italy

${ }^{\dagger}$ Current address: Department of Organic Chemistry, University of Geneva, Quai Ernest Ansermet 30, 1211 Geneva 4, Switzerland.

\section{Keywords}

lanthanides, luminescence, Circularly Polarized Luminescence, bio-sensing, DFT calculations, calorimetry

\begin{abstract}
The coordination features and signaling of the L-lactate ion by a $[\mathrm{Tb}(\mathrm{bpcd})]^{+}$(bpcd $=$N,N'-bis(2pyridylmethyl)-trans-1,2-diaminocyclohexane-N,N'-diacetate) complex have been investigated by means of a combination of techniques including total luminescence, calorimetry and circularly polarized luminescence. The L-lactate/[Tb(bpcd) $]^{+}$association constant, determined both by luminescence titration and isothermal titration calorimetry, indicates a weak interaction $(\log K=1.3$ 1.45) between the analyte and both enantiomers of the complex. Theoretical DFT calculations suggest that the most likely coordination of L-lactate to the possible stereoisomers of the $[\mathrm{Tb}(S, S \text {-bpcd })]^{+}$ complex (trans- $\mathrm{O}, \mathrm{O}$ or trans $-\mathrm{N}_{\mathrm{py}}, \mathrm{N}_{\mathrm{py}}$ ) is that involving the hydroxyl group.

The results on $[\mathrm{Tb}(\mathrm{rac} \text {-bpcd })]^{+}$as chiroptical luminescent probe of L-lactate underline the peculiar role of the chiral 1,2-diaminocyclohexane $(\mathrm{DACH})$ backbone. Indeed, the target anion is capable to induce CPL activity from the racemic mixture of Tb complexes containing DACH-based ligand. The same is not observed for the achiral analogue $[\text { Tb(bped) }]^{+}$(bped $=$N,N'-Bis(2Pyridylmethyl)ethylenediamine-N,N'-diacetate) complex which does not produce CPL activity,
\end{abstract}


likely because of the flexibility of the ethylenic group which allows an interconversion between different isomers which produce a null net CPL activity. Thanks to the differential quantum yield of the two diastereomeric species $(R, R)-\mathrm{L}$ and $(S, S)-\mathrm{L}$, one can use the racemic complex to reveal $\mathrm{L}$ lactate by measuring the induced CPL spectrum. Interestingly this has been demonstrated in a commercial complex solution for medical use, containing several electrolytes, namely Ringer's lactate.

\section{Introduction}

The detection of the lactate and the monitoring of its concentration is an important task, due to the crucial role of this molecule in several fields such as clinical diagnostics, sports medicine, food industry and biotechnology ${ }^{1}$. In particular, lactate is strongly connected to several diseases. For example, when sepsis is suspected in a patient, it is recommended to measure the lactate concentration promptly. ${ }^{2}$ Also, abnormally elevated lactate concentrations are revealed in subjects affected by Parkinson's disease ${ }^{3}$ and high level of serum lactate are also connected to a severe liver pathology. ${ }^{4}$ Furthermore, lactate is well known as a specific biomarker for specific types of cancers such as prostate and breast cancer. ${ }^{5}$ Finally, the quantity of lactate in food can be used as an indicator of freshness, stability and storage quality, as high level of it can be synonymous of microbial contamination. ${ }^{6}$ In this context, detection of the enantiomeric composition of L/D-lactate can reveal food adulterations, like the fraudulent addition of the synthetic racemate. Therefore, the constant need of low cost, simple, rapid, highly sensitive and reliable methods for lactate quantification is not surprising and enantiospecific response is a further desirable feature.

In this direction, total luminescence (TL) and circularly polarized luminescence (CPL) spectroscopies stemming from f-f transitions of trivalent lanthanide complexes ( $\mathrm{Ln}(\mathrm{III})=\mathrm{Sm}(\mathrm{III}), \mathrm{Eu}(\mathrm{III}), \mathrm{Gd}(\mathrm{III})$, $\mathrm{Tb}(\mathrm{III}), \mathrm{Dy}(\mathrm{III}), \mathrm{Yb}(\mathrm{III}))$ can be conveniently exploited, due to several advantages. Firstly, the interaction between the target anion (lactate) and the positively charged lanthanide cation can be signaled by a unique change of the TL features. In addition, CPL spectroscopy has proven to be particularly suitable to track interaction between luminescent molecular probes (even non-chiral or racemic ones) with chiral species, such as proteins, ${ }^{7,8}$ DNA, ${ }^{9}$ aminoacids, ${ }^{10-13}$ or chiral ions (lactate is a chiral anion) or molecules (sialic acid). ${ }^{14} \mathrm{CPL}$ efficiency is measured in terms of the dissymmetry factor (or $g_{\text {lum }}$ ), defined as: $g_{\text {lum }}=2\left(I_{\mathrm{L}}-I_{\mathrm{R}}\right) /\left(I_{\mathrm{L}+} I_{\mathrm{R}}\right)$ (with $I_{\mathrm{L}}$ and $I_{\mathrm{R}}$ the left- and right-polarized intensity, respectively). Secondly, since a good limit of sensitivity of the analytical method is recommended, a sizable value of the overall luminosity or brightness (B) in aqueous media must be 
reached. As $\mathrm{B}=\varepsilon \cdot \Phi$, with $\varepsilon$ molar absorption coefficient and $\Phi$ the overall luminescence quantum yield, the ligand should be capable to strongly absorb the exciting light (high value of $\varepsilon$ ) and efficiently transfer the excitation energy to the lanthanide ion (antenna effect). A proper choice of the ligand is also required in order to hamper the intrusion of solvent molecules in the metal ion inner coordination sphere. This phenomenon would increase the non-radiative quenching of the $\operatorname{Ln}(\mathrm{III})$ excited state by multiphonon relaxation processes, one of the main drawbacks, negatively affecting the intrinsic quantum yield $\left(\Phi_{\mathrm{Ln}}\right)$. In addition, since the excited states of $\mathrm{Tb}(\mathrm{III})$ are less sensitive to non-radiative vibrational quenching caused by high energy oscillators (primarily $\mathrm{O}-\mathrm{H}$ ), its complexes are suited for applications in aqueous media. Last, the large energy shift between absorbed and emitted radiations (in the case of ligand sensitization) and the very narrow emission bands allow the separation between $\operatorname{Ln}(\mathrm{III})$ luminescence and short-lived background fluorescence in complex. ${ }^{15}$ Also, the long emission lifetimes of $\operatorname{Ln}(\mathrm{III})$ ions (usually in the milliseconds range), can be exploited in order to minimize the interference from autofluorescence, via time-gated detection. ${ }^{16}$

We recently studied the coordination chemistry of $\mathrm{Eu}(\mathrm{III})$ and $\mathrm{Tb}(\mathrm{III})$ ions with ligands carrying the chiral 1,2-diaminocyclohexane (DACH) backbone, which have been suitably modified to form stable complexes in water. $^{17-20}$ In particular, we obtained the water soluble Tb-complex $\left(\left[\mathrm{Tb}(\mathrm{bpcd})\left(\mathrm{H}_{2} \mathrm{O}\right)_{\mathrm{x}}\right]^{+}\right.$, chart 1) characterized by strong Tb-based CPL activity upon excitation of the ligand. ${ }^{20}$ The chiral $\mathrm{H}_{2}$ bpcd (N,N'-bis(2-pyridylmethyl)-trans-1,2-diaminocyclohexane-N, $\mathrm{N}^{\prime}$ diacetic acid) (Chart 1), tightly binds Ln(III) ions, providing a dissymmetric environment, while at the same time leaving 2 - 3 sites available for binding to further ancillary ligands. For all these reasons, the Tb-complex can be considered a valuable CPL probe for important analytes in aqueous media. In the present contribution we have investigated the optical and chiroptical response of the aforementioned $\mathrm{Tb}$ complex to L-lactate by means of TL and CPL spectroscopy. The same experiments have been also carried out on the analogous Tb complex of the achiral ligand $\mathrm{H}_{2} \mathrm{bped}$ (Chart 1) in order to identify the role of the chiral DACH backbone on the optical and chiroptical luminescence signaling of L-lactate.

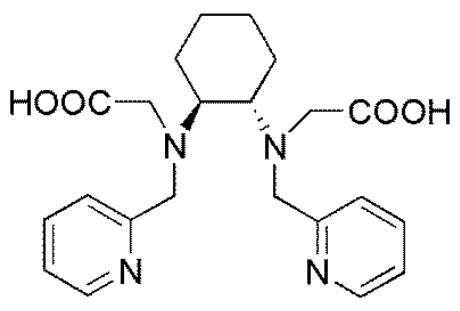

$\mathrm{H}_{2} \mathrm{bpcd}$

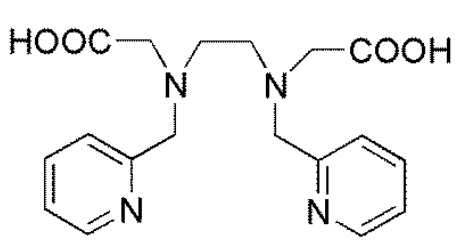

$\mathrm{H}_{2}$ bped

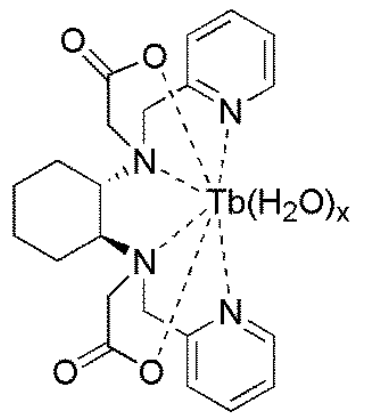

$\left[\mathrm{Tb}(\mathrm{bpcd})\left(\mathrm{H}_{2} \mathrm{O}\right)_{\mathrm{x}}\right]+; \mathrm{x}=2$ or 3 
Chart 1. Ligands and complex discussed in the present work. The ligand $\mathrm{H}_{2}$ bpcd has been prepared in its $(S, S),(R, R)$ and racemic forms. The coordinated water molecules in the $\mathrm{Tb}(\mathrm{III})$ complex can be easily replaced by an analyte.

DFT calculations, which have been previously applied successfully to get structural and thermochemical data for $f$-block metal complexes, ${ }^{18,21,22}$ are used in order to evaluate the relative stability of the 1:1 $\mathrm{Tb}(\mathrm{bpcd}) / \mathrm{L}-$ lactate adducts, when the ligand stereochemistry is $(S, S)$.

Further, the binding constants of these adducts have been determined by means of the BenesiHildebrand method applied on the $\mathrm{Tb}(\mathrm{III})$ luminescence emission spectra.

\section{Experimental Section}

$\mathrm{TbCl}_{3} \cdot 6 \mathrm{H}_{2} \mathrm{O}$ (Aldrich, 98\%) was stored under vacuum for several days at $80^{\circ} \mathrm{C}$ and then transferred in glove box.

$\mathrm{Tb}$ (bpcd)Cl was synthetized by following the procedure reported in literature. ${ }^{20}$

The luminescence (TL and CPL) experiments of L-lactate (Alfa Aesar 98\%) were carried out as follows: To a water solution of the $\mathrm{Tb}(\mathrm{III})$ complex $(6 \mathrm{mM})$, increasing quantities of a water solution of L-lactate $(2.3 \mathrm{M})$ were added. After each addition, the TL (in the 450-720 $\mathrm{nm}$ spectral range) and CPL (in the 530-570 $\mathrm{nm}$ spectral range) emission spectra and the ${ }^{5} \mathrm{D}_{4}$ excited state kinetics were collected. All the TL spectra have been normalized for the concentration of the Tb(III) ion.

\section{Calorimetry}

An independent determination of the formation constants and the related reaction enthalpy for the formation of L-lactate ternary complex with $[\mathrm{Tb}(\mathrm{rac}-\mathrm{bpcd})]^{+}$was performed by Isothermal Titration Calorimetry (ITC), which is a largely applied method ${ }^{23,24}$ to measure the heat involved in the species interaction.

The $[\mathrm{Tb}(\mathrm{rac} \text {-bpcd })]^{+}$complex solution was prepared by diluting stock solutions of the Tb chloride hexahydrate salt (Sigma-Aldrich) and the $\mathrm{H}_{2}$ bpcd ligand in its racemic form. The $\mathrm{Tb}$ content in the stock solution was determined by titration with EDTA and xylenol orange as indicator. The stock solution of 1-lactate was prepared by diluting its sodium salt (Aldrich 99\%). All solutions were prepared in ultrapure water (over $18 \mathrm{M} \Omega \cdot \mathrm{cm}$ at $298.15 \mathrm{~K}$ ) from a MilliQ system (ELGA Purelab UHQ) and the $\mathrm{pH}$ was adjusted to 7.0. 
The ITC experiment was carried out with a TA instruments TAM III thermostat equipped with a nanocalorimeter and an automatic titration syringe at $298.15 \mathrm{~K}$. The lactate solution (25 injections of $10 \mu \mathrm{L}$ of L-lactate $80 \mathrm{mM}$ ) was added under constant stirring ( $60 \mathrm{rpm})$ to a $0.7 \mathrm{ml}$ solution of [ $\mathrm{Tb}(\mathrm{rac}$ bpcd $)]^{+}(0.63 \mathrm{mM})$. The experiment was repeated three times to check the reproducibility of the data. The delay time between two consecutive injections was set to $12 \mathrm{~min}$, which was long enough to let the system reach thermal equilibrium. The reference cell was filled with MilliQ water with the $\mathrm{pH}$ adjusted to 7.0. According to the value of its stability constant $(\log \beta=11.35){ }^{20}$ the $[\mathrm{Tb}(\mathrm{rac}-\mathrm{bpcd})]^{+}$ species initially present in the cell were about $97 \%$ of the total species concentrations at pH 7.0. For each titration run, the experimental heats $\left(Q_{e x, j}\right.$, with $\left.j=1, \ldots n\right)$ were collected and corrected for the dilution heat $Q_{d i l, j}$, measured in a separate experiment. The net reaction heats, $Q_{o b s, j}=Q_{e x, j}-Q_{d i l, j}$, were analysed by the EST and Solverstat tools. ${ }^{25,26}$

\section{DFT calculations}

As the paramagnetic $\mathrm{Eu}(\mathrm{III})$ and $\mathrm{Tb}(\mathrm{III})$ complexes are rather difficult to model computationally, the analogues of the diamagnetic Y(III) ion have been studied. It has been shown that Y(III) complexes may serve as suitable models for the $\mathrm{Eu}(\mathrm{III})$ and $\mathrm{Tb}$ (III) analogues, ${ }^{27}$ consistently with the fact that its ionic radius differs from that of $\mathrm{Eu}(\mathrm{III})$ ion by only $0.02 \AA^{28}$ The structure of $[\mathrm{M}(S, S$ bpcd $\left.)\left(\mathrm{H}_{2} \mathrm{O}\right)_{5}\right]^{+}(\mathrm{M}=\mathrm{Y}(\mathrm{III}), \mathrm{La}(\mathrm{III}))$ has been previously optimized ${ }^{20}$ and two isomers (trans-O,O and trans $-\mathrm{N}_{\mathrm{py}}, \mathrm{N}_{\mathrm{py}}$, Chart $\mathrm{S} 1$ ) have been shown to be equally stable in solution. Furthermore, on the basis of the luminescence lifetime results and DFT calculations it has been proposed that also a hydration/dehydration equilibrium between species with 2 or 3 coordinated water molecules should be present. ${ }^{20}$ Geometry optimizations of both trans-O,O and trans $-\mathrm{N}_{\mathrm{py}}, \mathrm{N}_{\mathrm{py}}$ isomers of the [Y $(S, S$ bpcd)(S-lactate)] species with the ligand in the $(S, S)$ stereochemistry were carried out at DFT level in vacuum using the B3LYP 29,30 exchange-correlation functional. The $6-31+\mathrm{G}(d)$ basis set has been employed for the ligand atoms, while Y(III) ions were described by the quasi-relativistic small core Stuttgart-Dresden pseudopotential ${ }^{31}$ and the relative basis set. This level of theory has been previously demonstrated to provide correct geometries and thermochemical properties, maintaining the calculation feasible also with similar complex systems. ${ }^{18,21,32}$ All final geometries were checked to be minima by vibrational analysis. Solvent effects have been included by means of the PCM model. ${ }^{33}$ All calculations were carried out with Gaussian $16 .^{34}$ 


\section{Luminescence and decay kinetics}

Room temperature luminescence was measured with a Fluorolog 3 (Horiba-Jobin Yvon) spectrofluorometer, equipped with a Xe lamp, a double excitation monochromator, a single emission monochromator (mod. HR320) and a photomultiplier in photon counting mode for the detection of the emitted signal. All the spectra were corrected for the spectral response of the setup.

In decay kinetics measurements, a xenon microsecond flashlamp was used and the signal was recorded by means of multichannel scaling method. Experimental decay times were obtained using the convolution of the instrumental response function with an exponential function and the leastsquare-sum-based fitting program (SpectraSolve software package).

The binding interactions between L-lactate and $[\mathrm{Tb}(R, R \text {-bpcd })]^{+},[\mathrm{Tb}(S, S \text {-bpcd })]^{+}$and $[\mathrm{Tb}(\mathrm{bped})]^{+}$ were studied using the double reciprocal plot following the Benesi-Hildebrand equation:

$\mathrm{I}_{0} /\left(\mathrm{I}-\mathrm{I}_{0}\right)=\mathrm{I}_{0} /\left(\mathrm{I}_{\infty}-\mathrm{I}_{0}\right)+\mathrm{I}_{0} /\left\{K^{\prime} \cdot\left(\mathrm{I}_{\infty}-\mathrm{I}_{0}\right) \cdot[\right.$ L-lactate $\left.]\right\}$

where $\mathrm{I}_{0}, \mathrm{I}$, and $\mathrm{I}_{\infty}$ are the the emission intensity of $\mathrm{Tb}(\mathrm{III})$ at $546 \mathrm{~nm}$ considered in the absence of Llactate, at an intermediate L-lactate concentration and at a concentration of complete interaction, respectively. $K$ represents the binding constant and [L-lactate] is the L-lactate concentration.

\section{Circularly Polarized Luminescence}

CPL spectra were recorded with the home-made spectrofluoropolarimeter described previously. ${ }^{35}$ The spectra were recorded in $\mathrm{CD}_{3} \mathrm{OD}$ or $\mathrm{H}_{2} \mathrm{O}$ in $2.0-3.0 \mathrm{mM}$ (for $[\mathrm{Tb}(\mathrm{bpcd}) \mathrm{Cl}]$ ), under $254 \mathrm{~nm}$ irradiation using a $90^{\circ}$ geometry between the excitation and the detection directions.

\section{Results and discussion}

\section{L-lactate sensing experiments: Total Luminescence}

In figure 1 , the evolution of the Total Luminescence emission spectra of the complex $[\mathrm{Tb}(R, R$ bpcd $\left.)\left(\mathrm{H}_{2} \mathrm{O}\right)\right]^{+}$upon addition of L-lactate is presented. 


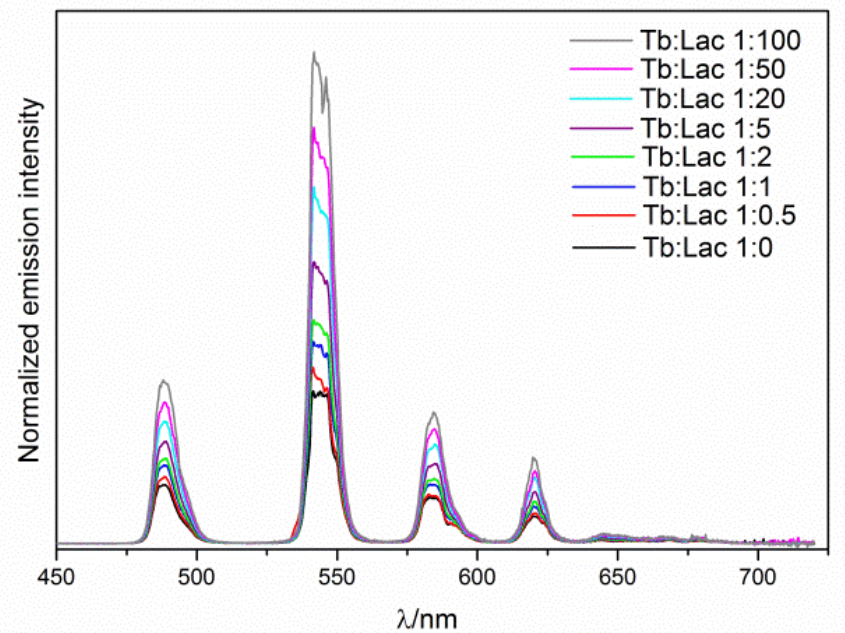

Figure 1. Evolution of the total luminescence emission spectra upon addition of the L-lactate anion, for complex $\left[\mathrm{Tb}(R, R \text {-bpcd })\left(\mathrm{H}_{2} \mathrm{O}\right)_{\mathrm{x}}\right]^{+}\left(\lambda_{\mathrm{exc}}=270 \mathrm{~nm}\right)$.

Thanks to the excitation of the ligand around $270 \mathrm{~nm}$ followed by ligand to $\mathrm{Tb}(\mathrm{III})$ energy transfer, the typical visually green emission originating from the transition of the $\mathrm{Tb}(\mathrm{III})$ ion is collected (figure 1). Upon addition of L-lactate the intensity of all $\mathrm{Tb}(\mathrm{III})$ emission bands increases until reaching a plateau when the molar ratio between L-lactate and the metal is around 100. The same experiments have been carried out on the $\mathrm{Tb}(\mathrm{III})$ complexes of $(S, S)-\mathrm{H}_{2}$ bpcd and $\mathrm{H}_{2}$ bped ligands (Chart 1) and the increase of the relative emission intensity at $546 \mathrm{~nm}$ (the maximum of the ${ }^{5} \mathrm{D}_{4} \rightarrow{ }^{7} \mathrm{~F}_{5}$ band) as a function of the L-lactate molar ratio is shown in figure 2 (a). In addition, the $\mathrm{Tb}(\mathrm{III}){ }^{5} \mathrm{D}_{4}$ excited state lifetimes have been also measured after each addition of L-lactate. All the decay curves are well fitted to a single exponential function and the values of the observed lifetimes are reported as a function of the L-lactate molar ratio (Figure 2(b)). Upon interacting with the chiral anion, the two enantiomeric complexes give rise to a diastereomer pair, which we may shortly define $(R, R)-\mathrm{L}$ and $(S, S)-\mathrm{L}$, and are characterized by potentially different photophysical properties. 
(a)

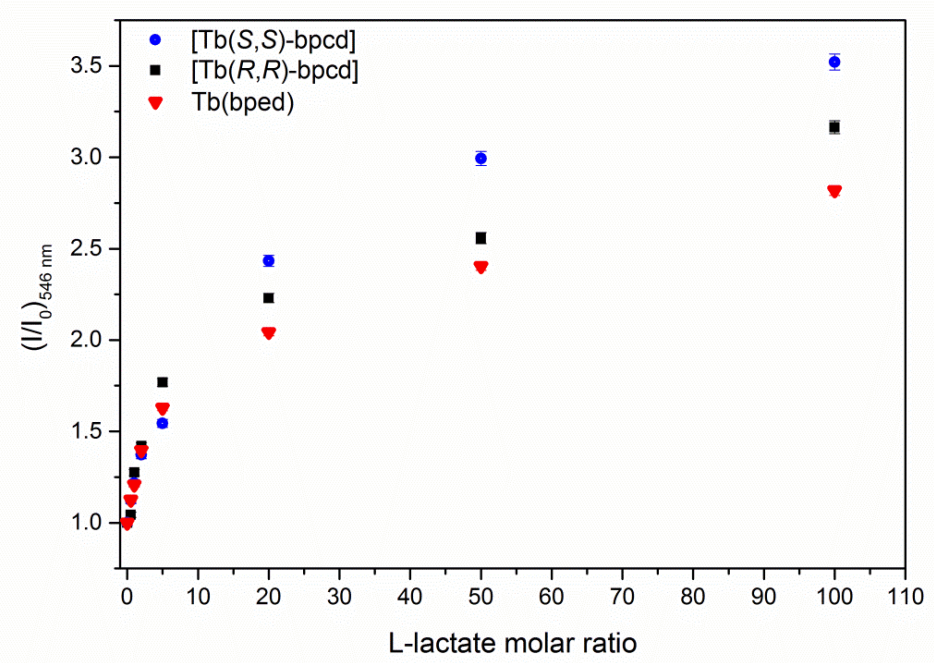

(b)

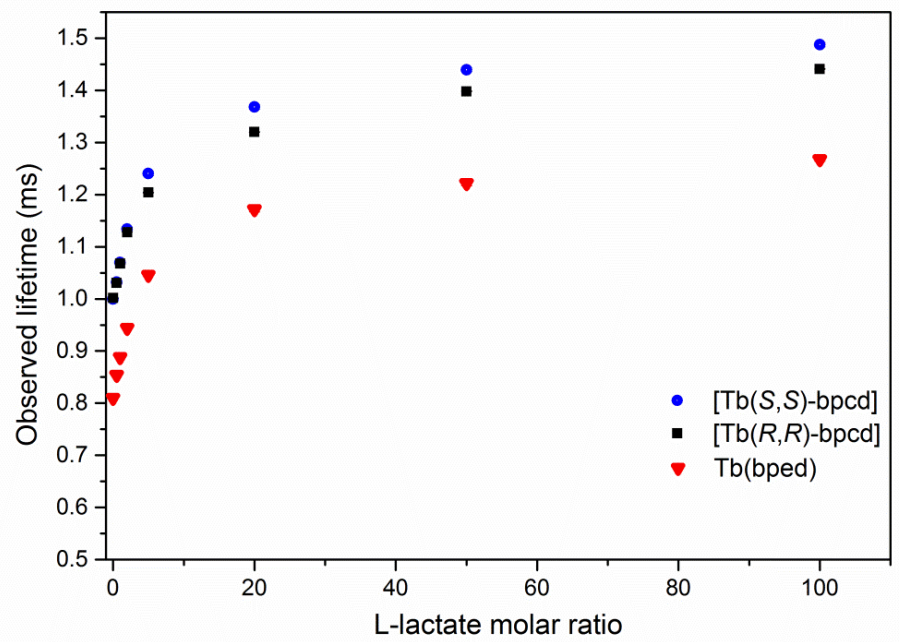

Figure 2. (a) Relative emission intensity at $546 \mathrm{~nm}$ and (b) Observed lifetime as a function of the Llactate to metal molar ratio (L-lactate molar ratio) for Tb complexes with $(S, S)$-bpcd, $(R, R)$-bpcd and bped ligands $\left(\mathrm{I}_{0}=\right.$ emission intensity at $546 \mathrm{~nm}$ of the starting $\mathrm{Tb}(\mathrm{III})$ complex).

As far as the curve profile is concerned, for all the investigated complexes a logarithmic-like trend is observed both in figures $2 \mathrm{a}$ and $2 \mathrm{~b}$. As expected, the relative curves of the $\left[\mathrm{Tb}(\mathrm{rac} \text {-bpcd) }]^{+}\right.$(not reported) fall in the middle of the curves of the two enantiomers. For this reason, under this aspect the racemic complex will not be discussed further. Whilst the evolution of the lifetime values is very similar for the two enantiomeric complexes $\left([\mathrm{Tb}(S, S \text {-bpcd })]^{+}\right.$and $\left.[\mathrm{Tb}(R, R \text {-bpcd })]^{+}\right)$, the increase of the relative intensity of the ${ }^{5} \mathrm{D}_{4} \rightarrow{ }^{7} \mathrm{~F}_{5}$ emission band (around $546 \mathrm{~nm}$ ) is more sensitive to the presence of L-lactate in the case of the $\left[\mathrm{Tb}(S, S \text {-bpcd) }]^{+}\right.$complex (Fig.2a). On the other hand, the achiral 
$[\mathrm{Tb}(\mathrm{bped})]^{+}$complex is less sensitive towards L-lactate and the observed lifetime during the titration experiment is always lower, in comparison with the lifetime values of the enantiomeric pair containing the bpcd ligand. The increase of both emission intensity and the observed lifetimes for all the complexes under investigation can be tentatively explained by assuming a replacement of the inner sphere water molecules by the target anion. This phenomenon should reduce the non-radiative quenching of the $\mathrm{Tb}$ (III) excited state caused by the presence in the close proximity of the metal ion of $\mathrm{OH}$ groups with high vibrational energy. ${ }^{36}$ On the basis of a similar reasoning, the shorter observed lifetimes in the case of $[\mathrm{Tb}(\mathrm{bped})]^{+}$compound, can be ascribed to the presence of a higher number of water molecules close to the metal ion.

In order to ascertain this point, the decay curves of the $\mathrm{Tb}(\mathrm{III}){ }^{5} \mathrm{D}_{4}$ excited state in $\mathrm{H}_{2} \mathrm{O}$ and $\mathrm{D}_{2} \mathrm{O}$ for $[\mathrm{Tb}(\mathrm{bped})]^{+}$complex, are shown in figure $\mathrm{S} 1$.

The curves, well fitted to a single exponential, present a decay constant of 0.81(1) ms and 1.55(1) ms in water and $\mathrm{D}_{2} \mathrm{O}$, respectively. The number of water molecules in the close proximity to the metal ion (hydration number) was calculated by the Horrock's equation. ${ }^{37,38}$ As this number [2.5(5)] is the same as the one calculated previously for $[\mathrm{Tb}(\mathrm{rac} \text {-bpcd })]^{+}$complex $(2.6(5)),{ }^{20}$ the reason of the aforementioned discrepancy should be sought elsewhere and this point will be discussed in detail later in this contribution.

Finally, the binding constants between L-lactate and $[\mathrm{Tb}(\mathrm{bpcd})]^{+}$and $[\mathrm{Tb}(\mathrm{bped})]^{+}$complexes have been calculated by the Benesi-Hildebrand method. ${ }^{39}$ In Figure 3 , the plot of $\mathrm{I}_{0} /\left(\mathrm{I}_{0}-\mathrm{I}\right)$ vs. [L-lactate] ${ }^{-1}$ for the $[\mathrm{Tb}(S, S \text {-bpcd })]^{+}$complex, shows a good linear relationship, characteristic of $1: 1$ binding. The binding constant can be calculated from the ratio of intercept/slope, ${ }^{40}$ and its value is $22.6(1) \mathrm{M}^{-1}$. The same calculation performed on the $\left[\mathrm{Tb}(R, R \text {-bpcd) }]^{+}\right.$and $[\mathrm{Tb}(\mathrm{bped})]^{+}$complexes (Figure $\mathrm{S} 2$ ) provide similar binding constants [28.6(1) and 28.2(1) $\mathrm{M}^{-1}$, respectively]. In the light of these results, the adduct between L-lactate and the enantiomeric pair of complexes reveals a similar stability, slightly higher in the case of the $(R, R)$ isomer. 


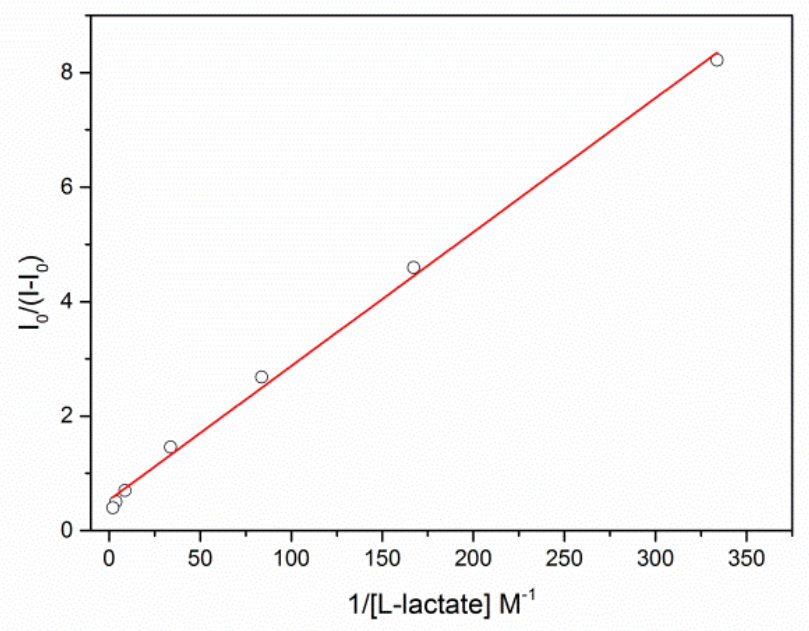

Figure 3. Benesi-Hildebrand plot against $[\mathrm{L}-\mathrm{lactate}]^{-1}$ for the $[\mathrm{Tb}(S, S \text {-bpcd })]^{+}$complex. $\mathrm{I}_{0}$ is the emission intensity at $546 \mathrm{~nm}$ of the starting complex; I is the emission intensity at $546 \mathrm{~nm}$ of the Llactate:complex adduct after each addition of the analyte.

The ITC output during the titration of a $[\mathrm{Tb}(\mathrm{rac}-\mathrm{bpcd})]^{+}$solution with the L-lactate solution is reported in Figure 4a (the area of the peaks corresponds to $Q_{\mathrm{ex}, \mathrm{j}}$ ). In Figure $4 \mathrm{~b}$ the total heat evolved at the $j^{\text {th }}$ injection ${ }^{l}\left(Q_{c u m, j}\right)$ is reported along with the values calculated with the $\log K$ and $\Delta H$ values reported in Table 1. Both, enthalpy and entropy for the formation of [ $\mathrm{Tb}$ (rac-bpcd)L-lactate] are positive, which is often found in charge neutralization reactions in aqueous solutions. ${ }^{41,42}$ The obtained formation constant is in good agreement with that obtained by fluorimetric titration and very similar to the third stepwise formation constant of $\left[\mathrm{Tb}(\mathrm{L}-\text {-lactate })_{3}\right]$ and $\left[\mathrm{Eu}(\mathrm{L}-\text {-lactate })_{3}\right]$ complexes (Table 1). ${ }^{43-45}$

In a previous work $^{20}$ we demonstrated that the complex with bpcd is present in two forms energetically equivalent (trans-O,O and trans $-\mathrm{N}_{\mathrm{py}}, \mathrm{N}_{\mathrm{py}}$ ). The formation of the ternary complex with lactate implies the removal of two water molecules from these species to produce final complexes where the lanthanide is completely dehydrated and the lactate act as chelate, as suggested by the longer luminescence lifetimes measured when increasing the lactate/Tb molar rations. The lactate anion can chelate lanthanides either through the carboxylate group or the hydroxo/carboxylate oxygens. ${ }^{46}$ Furthermore, it has been proposed ${ }^{45}$ that in $[\text { Eu(lactate) }]^{2+}$ complex the anion is coordinated through carboxyl oxygen and with the deprotonated hydroxyl group (hydroxylate). On the contrary, hydroxyl group was considered protonated in the $\left[\mathrm{Eu}(\text { lactate })_{2}\right]^{+}$and $\left[\mathrm{Eu}(\mathrm{lactate})_{3}\right]$ species. ${ }^{45,46}$ We calculated the minimum energy structures for the two possible chelation modes of

${ }^{1} Q_{c u m, j}=\sum_{1}^{j} Q_{o b s, j}$ 
the stable coordination isomers with the $\mathrm{Y}(\mathrm{III})$ ion (Figure 5) considering the ligand in $(S, S)$ configuration and the hydroxyl group to be protonated. The Y-O (lactate) bond lengths reported in Table 2 show that the carboxylate group interacts more strongly with $[\mathrm{Y}(S, S \text {-bpcd })]^{+}$unit when the coordination occurs both through the carboxylate and hydroxyl groups as it presents a shorter average $\mathrm{Y}-\mathrm{O}$ bond distance with respect to the other coordination mode. The calculated energy difference in gas phase and PCM solvent for the a-d isomers (Table S1) also indicates that the carboxyl- hydroxyl coordination is more favored. The trans-O,O isomers have been also studied in presence of 4 explicit water molecules (Figure $5 \mathrm{e}, \mathrm{f}$ ). The $\mathrm{Y}-\mathrm{O}$ bond distance is further reduced in the e isomer, and it results that the hydroxyl group is hydrogen bonded to an outer sphere water molecule. On the contrary, the $\mathrm{Y}-\mathrm{O}$ bond is slightly elongated in the $\mathrm{f}$ isomer with respect to $\mathrm{b}$ structure. The $\Delta \mathrm{E}$ calculated is still favorable to the hydroxo- carboxy- coordination, in agreement with previous results found for the $\left[\mathrm{La}(\text { lactate })_{\mathrm{n}}\right]^{3-\mathrm{n}}$ complexes (Table $\left.\mathrm{S} 1\right)$.

a)

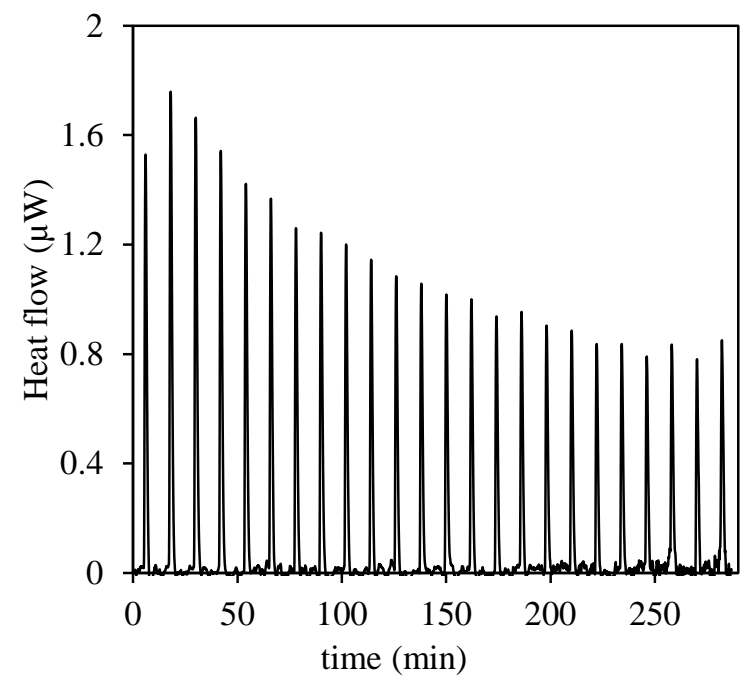

b)

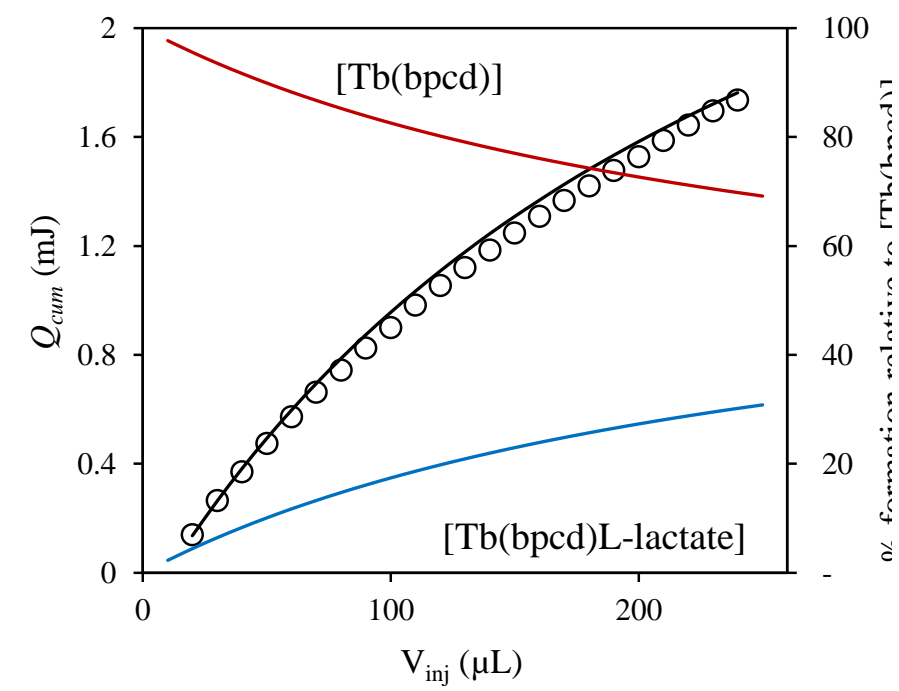

Figure 4. a) ITC titration raw output signal (positive sign here corresponds to an exothermic reaction) the obtained $Q_{e x}$ have been subtracted by the heat obtained by the dilution experiment with a L-lactate solution at the same concentration (titration conditions in Methods section); b) experimental (circles) and calculated (solid line) cumulative heat $\left(Q_{c u m, j}=\sum_{1}^{j} Q_{o b s, j}\right) v s$. total added lactate volume $\left(\mathrm{V}_{\mathrm{inj}}\right)$. The calculated speciation is also shown. 
Table 1. Equilibrium constant and thermodynamic parameters for the formation of $[\mathrm{Tb}(\mathrm{rac}-\mathrm{bpcd}) \mathrm{L}-$ lactate] complex $(\mathrm{T}=298.15 \mathrm{~K}, \mathrm{I}=0.1 \mathrm{M} \mathrm{NaCl})$, determined through ITC. Stepwise formation constants for the reaction $\left[\operatorname{Ln}(\text { lactate })_{2}\right]+$ lactate $\leftrightarrows\left[\operatorname{Ln}(\text { lactate }]_{3}\right]$ with $\mathrm{Ln}=\mathrm{Eu}^{3+}, \mathrm{Tb}^{3+}(\mathrm{T}=298.15 \mathrm{~K}$, $\left.\mathrm{I}=0.2 \mathrm{M} \mathrm{NaClO}_{4},{ }^{43} 0.1 \mathrm{M} \mathrm{NaCl}\right) .{ }^{44,45}$ Charges omitted for clarity.

\begin{tabular}{clccc}
\hline Reaction & \multicolumn{1}{c}{$\begin{array}{c}\Delta G \\
\text { logK }\end{array}$} & $\begin{array}{c}\Delta H \\
\left(\mathrm{~kJ} \mathrm{~mol}^{-1}\right)\end{array}$ & $\begin{array}{c}\Delta S \\
\left(\mathrm{~kJ} \mathrm{~mol}^{-1}\right)\end{array}$ & $\left(\mathrm{J} \mathrm{K}^{-1} \mathrm{~mol}^{-1}\right)$ \\
\hline$[\mathrm{Tb}($ rac-bpcd $)]+$ L-lactate $\leftrightarrows[\mathrm{Tb}($ rac-bpcd $)$ L-lactate $]$ & $1.30(9)$ & $-7.0(1)$ & $14.44(5)$ & $72.4(1)$ \\
& $1.35 / 1.45^{*}$ & $-7.7 /-8.3$ & - & - \\
\hline$\left[\mathrm{Tb}(\text { lactate })_{2}\right]+$ Lactate $\leftrightarrows\left[\mathrm{Tb}(\text { lactate })_{3}\right]$ & $1.18^{43}$ & -6.7 & - & - \\
{$\left[\mathrm{Eu}(\text { lactate })_{2}\right]+$ Lactate $\leftrightarrows\left[\mathrm{Eu}(\text { lactate })_{3}\right]$} & $1.15^{44}$ & -6.6 & - & - \\
\hline
\end{tabular}

*from fluorimetric titration 
a)

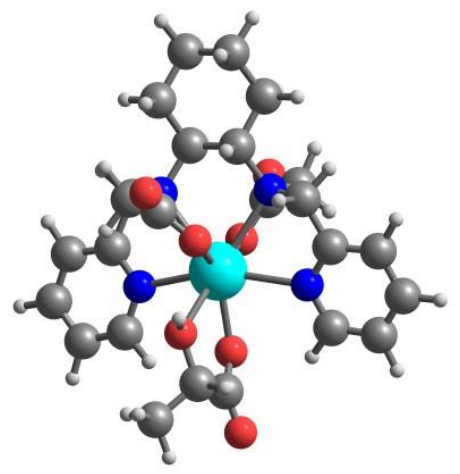

C)

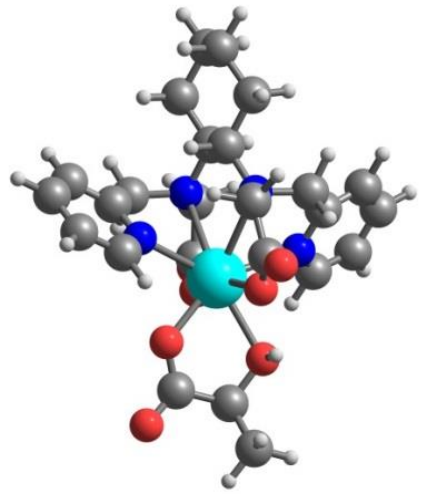

e)

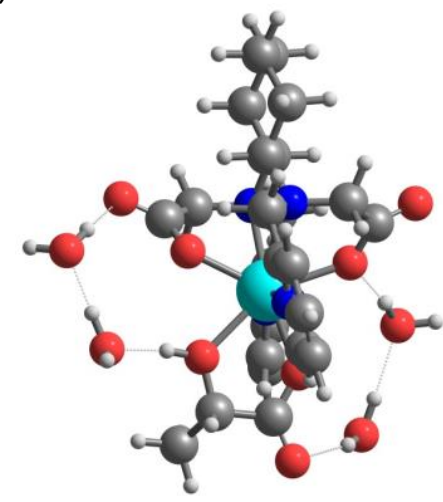

b)

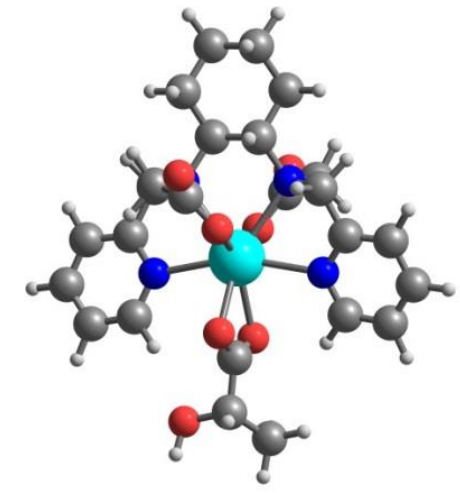

d)

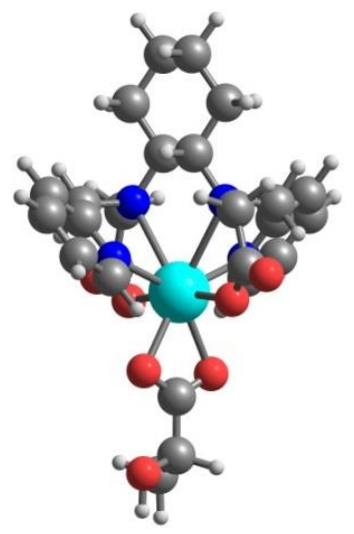

f)

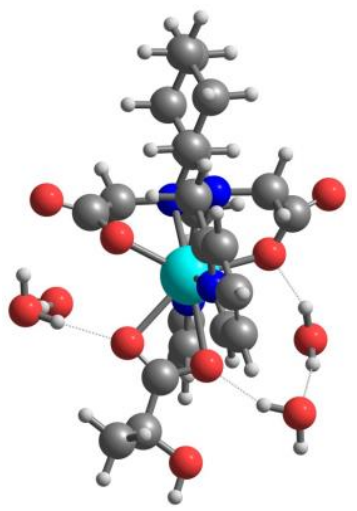

Figure 5. Minimum energy structures of the $[\mathrm{Y}(S, S$-bpcd $) \mathrm{L}-$ lactate $]$ complex. trans-O,O isomer: a) $\mathrm{O}_{\text {hydoxo }}, \mathrm{O}$ carboxy chelate, b) lactate $\mathrm{O}_{\text {carboxy }}$ chelate. trans $-\mathrm{N}_{\mathrm{py}}, \mathrm{N}_{\text {py }}$ isomer: c) lactate $\mathrm{O}_{\text {hydoxo }}, \mathrm{O}_{\text {carboxy }}$ chelate, d) lactate $\mathrm{O}_{\text {carboxy }}$ chelate. Structures e) and f) correspond to structures a) and b) optimized with 4 additional solvation water molecules. 
Table 2. Y-O distances $(\AA)$ for the structures reported in Figure 5. For the structures $b, d$ and $f$ the average $\mathrm{Y}-\mathrm{O}$ distance is reported.

\begin{tabular}{|c|c|c|}
\hline Structure & Ln-O ${ }_{\text {carboxy }}$ & Ln-O \\
\hline $\mathrm{a}$ & 2.274 & 2.505 \\
\hline $\mathrm{b}$ & 2.450 & - \\
\hline $\mathrm{c}$ & 2.219 & 2.452 \\
\hline $\mathrm{d}$ & 2.352 & - \\
\hline e & 2.250 & 2.428 \\
\hline $\mathrm{f}$ & 2.482 & - \\
\hline
\end{tabular}

L-lactate sensing: Circularly Polarized Luminescence

As previously observed, the $\mathrm{Tb}(\mathrm{III})$ complex with the chiral ligand bpcd shows a strong CPL activity (value for $g_{\text {lum }}$ around 0.07 at the peak of the $546 \mathrm{~nm}$ band). ${ }^{20}$ The change of the CPL signal during the titration with L-lactate is shown in Figure 6, for both enantiomers and for the racemic complexes.

(a)

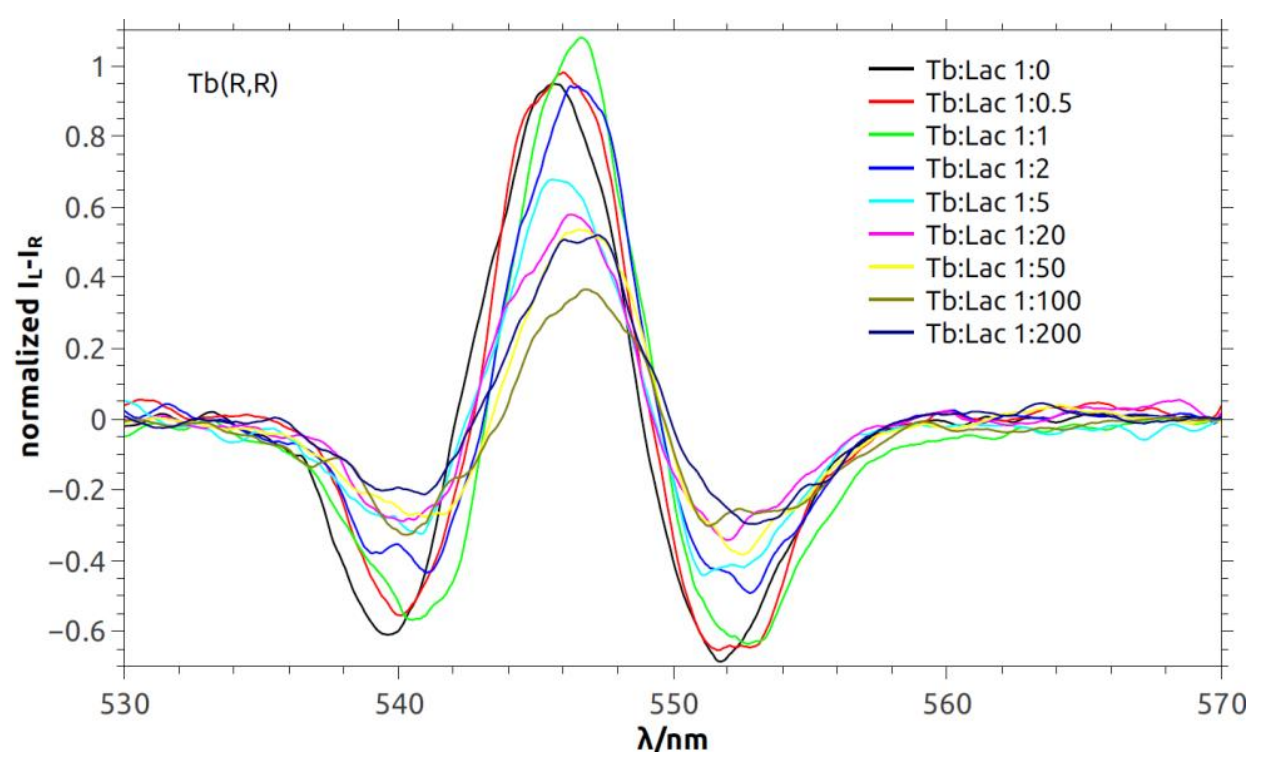


(b)

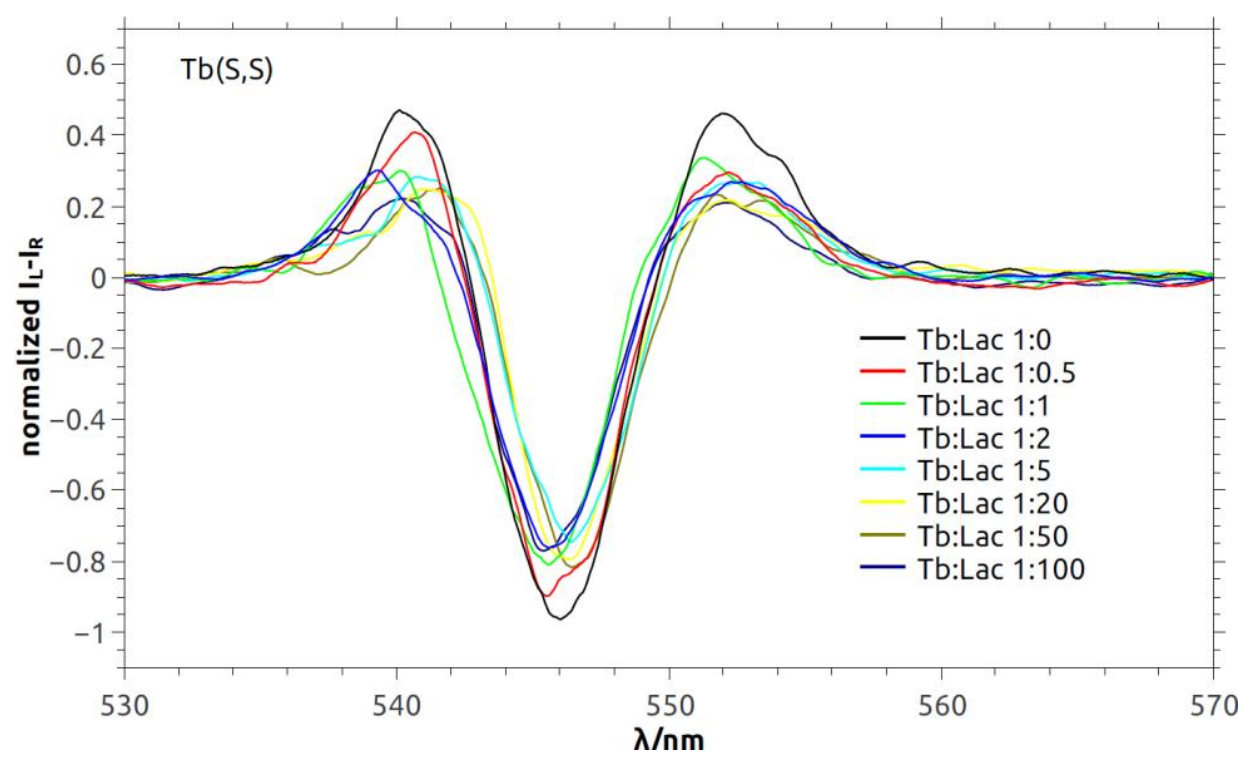

(c)

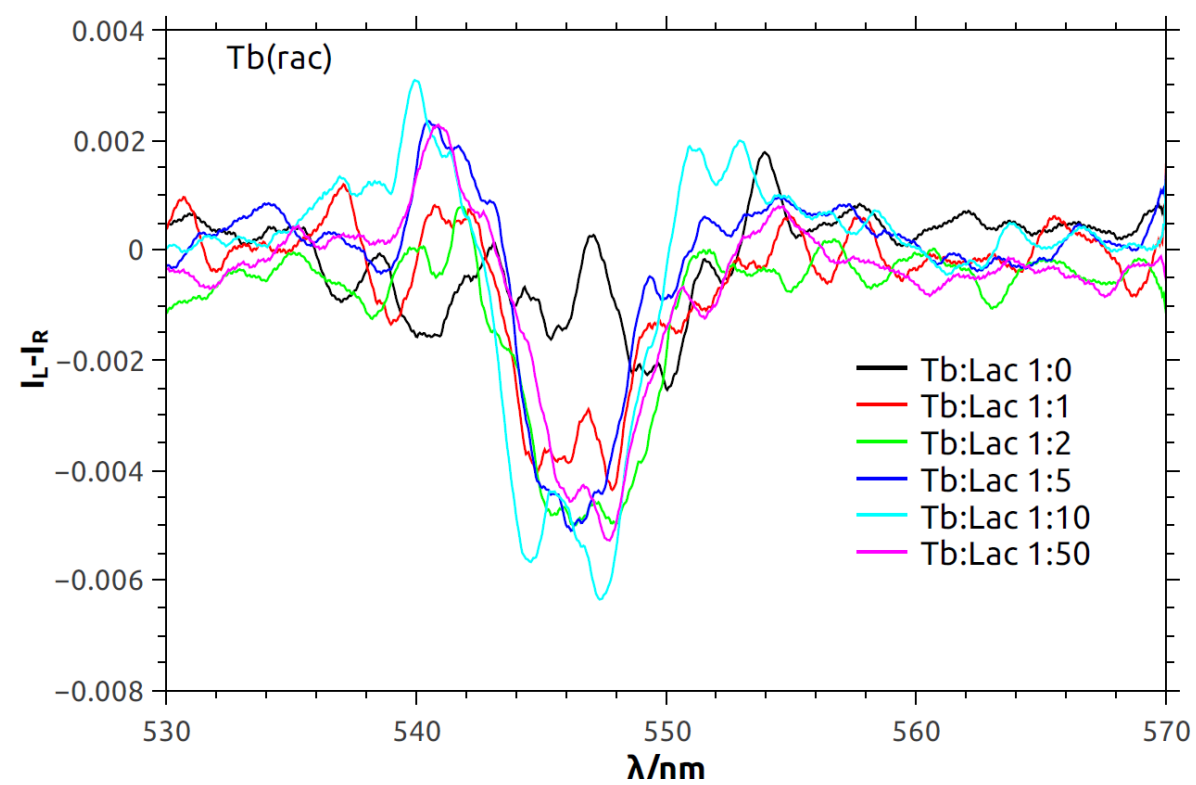

Figure 6. Normalized CPL spectra of $[\mathrm{Tb}(\mathrm{bpcd})]^{+}$complex upon addition of L-lactate for (a) the ligand with $(R, R)$ stereochemistry, (b) the ligand with $(S, S)$ stereochemistry and (c) the racemic ligand. All the CPL spectra relative to the enantiopure complexes are normalized to the first titration point (namely the 1:0 case).

Figure 6 shows a close-up relative to the ${ }^{5} \mathrm{D}_{4} \rightarrow{ }^{7} \mathrm{~F}_{5}$ multiplet, whose multiplicity becomes partly resolved, in contrast to the TL counterpart, thanks to some sign alternation of the dichroic signal. For both enantiomers of the complex, upon addition of the target anion, the dichroic signal decreases: this means that the adduct with lactate is at the same time more emissive (see Figure 2) but less CPLactive. 
This decrease is more prominent for the complex with $(R, R)$ stereochemistry. In fact, the value of CPL at $546 \mathrm{~nm}$, normalized to the total emission, shows a $50 \%$ variation from 0 to 100 equivalents of L-lactate added, while in the case of the complex with $(S, S)$ stereochemistry the variation is only around $17 \%$. In addition, the $g_{\text {lum }}$ factor reaches a constant value upon the addition addition of Llactate in 20-50 eq. excess.

During the titration of the racemic complex $[\mathrm{Tb}(\mathrm{rac} \text {-bpcd })]^{+}$, L-lactate interacts with one enantiomer as much as it does with the other one, on account of the very similar binding constants found in the previous section. This means that free $(R, R)$ and $(S, S)$ yield to the bound diastereomer pair $(R, R)-\mathrm{L}$ and $(S, S)$-L to the same extent. i.e. the ratios $(R, R):(S, S)$ and $(R, R)-\mathrm{L}:(S, S)$-L remain both constantly close to unity. The CPL signals of the two enantiomers of the free complexes will perfectly balance and cancel out. On the contrary, for the diastereomeric adducts, being $(S, S)$-L more emissive than $(R, R)-\mathrm{L}$ and at the same time the latter less CPL-active than the former one, the total CPL signals do not cancel and we must expect that the signal of $(S, S)-\mathrm{L}$ diastereomer dominates, which is exactly what we observed (Figure 6c).

The differences in TL (including lifetimes) and CPL for pair $(R, R)-\mathrm{L}$ and $(S, S)-\mathrm{L}$ witness the significant variations in the first coordination sphere for the two diastereomers, possibly both in terms of water coordination and of geometry.

As previously documented, ${ }^{20}$ the ligands bped and bpcd show similar protonation constants and, as far as the stabilities of the respective $\mathrm{Gd}(\mathrm{III})$ and $\mathrm{Eu}(\mathrm{III})$ complexes are concerned, similar formation constants are measured. From a stereochemical point of view, both bped and rac-bpcd can generate a pair of similar enantiomeric complexes: $\lambda$ and $\delta$ conformations, for the dynamically racemic $[\operatorname{Ln}(\text { bped })]^{+}$and $(R, R)+(S, S)$ configurations, for $[\operatorname{Ln}(\text { rac-bpcd })]^{+}($Chart 2$)$. The co-presence of the $\lambda$ and $\delta$ conformations in solution is supported by DFT calculations carried out for [Ln(bped)Llactate] complex which predict a similar stability of the $\lambda-\mathrm{L}$ and $\delta-\mathrm{L}$ adducts and the possibility of fast interconversion (Figure S3).

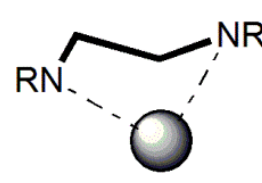

$\delta$

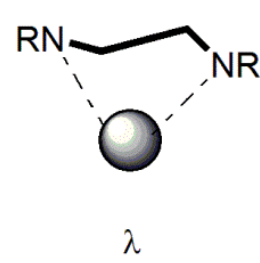

$\lambda$

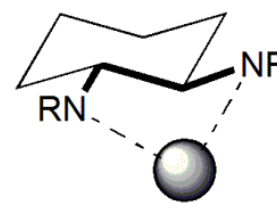

$(R, R)$

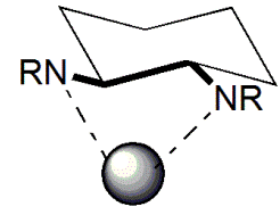

$(S, S)$ 
Chart 2. $\lambda$ and $\delta$ enantiomers of bped-based complexes (left) and $(R, R)$ and $(S, S)$ enantiomers of racbpcd-based complexes (right).

All this suggests both a similar coordination chemistry of these ligands and similar optical and chiroptical response towards L-lactate. Surprisingly, the titration of $[\mathrm{Tb}(\mathrm{bped})]^{+}$complex with Llactate does not produce any CPL activity (Figure S4), this could be related to the distribution of the different isomers in rapid equilibrium, as suggested by the small energy differences in Figure S3.

In order to deepen the reasons for such different behavior, we decided to investigate in detail the coordination geometry of the metal ion bound to bped and bpcd ligands. In this context, $\mathrm{Eu}(\mathrm{III})$ is considered a valuable structural probe as its $f$-f luminescence is strongly connected with the site symmetry of the metal ion. As the ionic size of $\mathrm{Tb}$ (III) and $\mathrm{Eu}(\mathrm{III})$ are quite similar, all the structural conclusion arising from the Eu(III) luminescence in the bped and bpcd-based complexes can be extended to their analogues of $\mathrm{Tb}(\mathrm{III})$. In this context, the synthesis of $[\mathrm{Eu}(\mathrm{rac}-\mathrm{bpcd})]^{+}$and $[\mathrm{Eu}(\mathrm{bped})]^{+}$complexes was performed and their luminescence emission spectra were collected in aqueous solution (Figure 7).

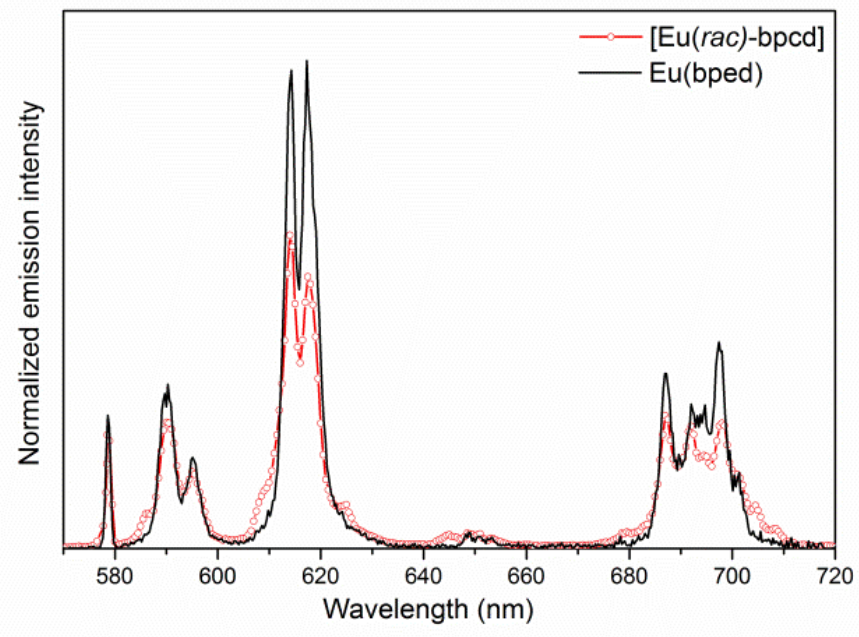

Figure 7. Luminescence emission spectra of $[\mathrm{Eu}(\mathrm{rac} \text {-bpcd })]^{+}$(red circles) and $[\mathrm{Eu}(\mathrm{bped})]^{+}$(black line) complexes, normalized to the area of the ${ }^{5} \mathrm{D}_{0} \rightarrow{ }^{7} \mathrm{~F}_{1}$ band, both $1 \mathrm{mM}$ in water upon excitation at $270 \mathrm{~nm}$.

As previously reported from the inspection of the $[\mathrm{Eu}(\mathrm{rac} \text {-bpcd })]^{+}$luminescence emission spectrum, ${ }^{20}$ a $C_{1}$ point symmetry of the metal ion is suggested. Since the emission spectrum of $[\mathrm{Eu}(\mathrm{bped})]^{+}$is similar to the one of $[\mathrm{Eu}(\mathrm{rac}-\mathrm{bpcd})]^{+}$, the same point symmetry of the metal ion can be assumed in both complexes. Nevertheless, the two luminescence emission spectra show one significant difference: the value of the asymmetry ratio ${ }^{47,48}$ : 


$$
\mathrm{R}=\frac{I\left({ }^{5} D_{0} \rightarrow{ }^{7} F_{2}\right)}{I\left({ }^{5} D_{0} \rightarrow{ }^{7} F_{1}\right)}
$$

which is related to the degree of asymmetry of the coordination polyhedron around the Eu(III) ion. $\mathrm{R}$ is 2.72 for $[\mathrm{Eu}(\mathrm{rac}-\mathrm{bpcd})]^{+}$and 3.48 for $\left.\mathrm{Eu}(\mathrm{bped})\right]^{+}$.

We strongly believe that the different chiroptical behavior detected during the titration of $[\mathrm{Tb}(\mathrm{rac}$ bpcd $)]^{+}$and $[\mathrm{Tb}(\text { bped })]^{+}$with L-lactate could be related with the different coordination geometry connected with the degree of distortion of their metal coordination sphere. The same reasoning can be adopted in order to justify the discrepancy of the decay constants (see above) during the same titration experiments.

With a view of possible practical applications, we investigated the behavior of $[\mathrm{Tb}(\mathrm{rac}-\mathrm{bpcd})]^{+}$in a complex L-lactate-based matrix. We used a commercial Ringer's lactate solution (Fresenius Kabi) used in common clinical practice to treat metabolic acidosis and to replace electrolytes and fluids after blood losses. This solution contains sodium L-lactate $(28.3 \mathrm{mM})$ in water alongside with $\mathrm{NaCl}$ $(6.0 \mathrm{~g} / \mathrm{L}), \mathrm{KCl}(0.40 \mathrm{~g} / \mathrm{L})$ and $\mathrm{CaCl}_{2} \cdot 2 \mathrm{H}_{2} \mathrm{O}(0.27 \mathrm{~g} / \mathrm{L})$. By adding to this solution $[\mathrm{Tb}(\mathrm{rac}-\mathrm{bpcd})]^{+}$to obtain a $5 \mathrm{mM}$ solution (1:5.4/Tb(bpcd):L-lactate). As expected, this solution shows a CPL spectrum (Figure 8) in agreement with the titration curves (Figure $6 \mathrm{c}$ ), both in terms of shape and intensity ( $g_{\text {lum }}$ $\left.\sim 6 \cdot 10^{-3}\right)$, thus suggesting the selectivity of $[\mathrm{Tb}(\mathrm{rac} \text {-bpcd })]^{+}$towards the target anion even in real complex matrices. It should be emphasized that in Ringer's solution, L-lactate is the only chiral species and for this reason, it is ultimately the only possible responsible for the CPL signal from $[\mathrm{Tb}(\mathrm{rac}-\mathrm{bpcd})]^{+}$.

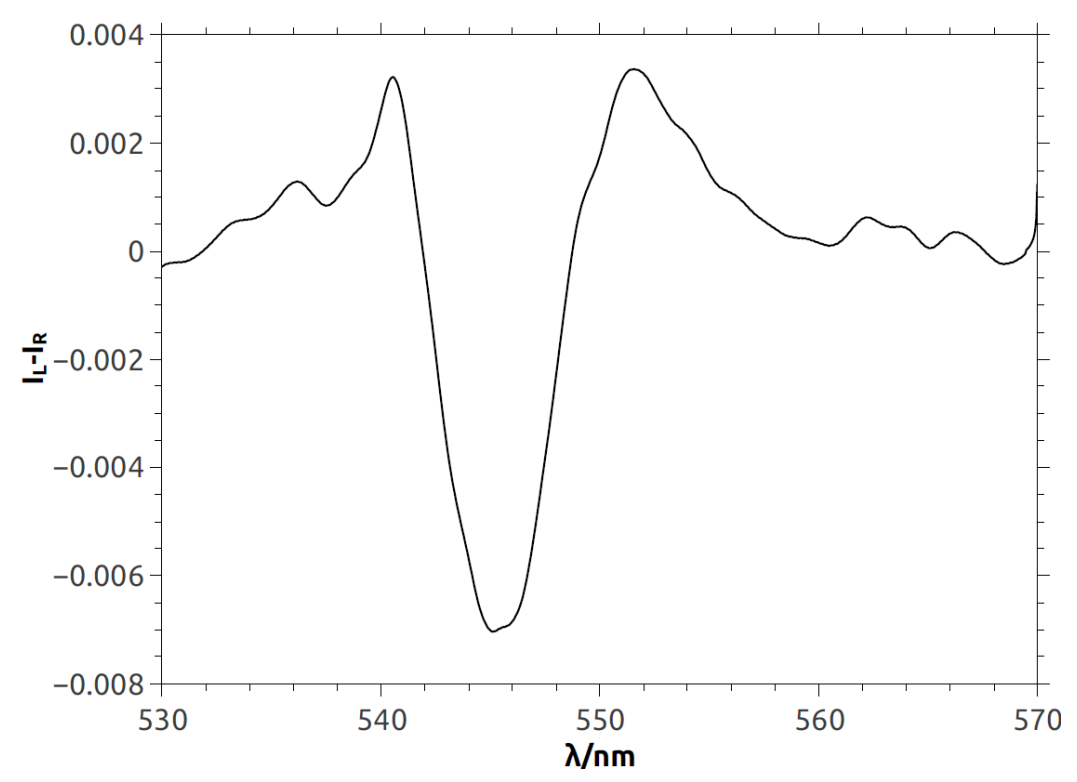


Figure 8. CPL spectrum of $[\mathrm{Tb}(\mathrm{rac}-\mathrm{bpcd})]^{+}(5 \mathrm{mM})$ in a commercial Ringer's lactate solution.

\section{Conclusions}

By means of a combination of techniques, we demonstrated that lactate reversibly binds $[\mathrm{Tb}(\mathrm{bpcd})]^{+}$ complex, displacing the water molecules completing $\mathrm{Tb}(\mathrm{III})$ coordination sphere in the pristine complex. The $[\mathrm{Tb}(\mathrm{bpcd})]^{+}$complex is chiral, as it incorporates trans-1,2-diaminocyclohexane, which is commercially available and rather inexpensive in both enantiomeric forms. The two enantiomers of $[\mathrm{Tb}(\mathrm{bpcd})]^{+}$bind L-lactate to a very similar extent, but the luminescence lifetimes for the two diastereomeric adducts $(R, R)-\mathrm{L}$ and $(S, S)-\mathrm{L}$ are very different, possibly on account of different geometries or different dynamics around the emitting center.

The formation constant of the ternary $[\mathrm{Tb}(\mathrm{rac}$-bpcd)L-lactate] complex has been determined both by luminescence titration and isothermal titration calorimetry. The data obtained by the two independent techniques are in good agreement and show that the L-lactate interacts weakly with the complex $(\log K$ $=1.3-1.45)$. The associated enthalpy and entropy terms, both positive, are also compatible with the complex formation between charged species in water. Further work is envisaged to assess the affinity of the $[\mathrm{Tb}(\mathrm{bpcd})]^{+}$complex for lactate in conditions close to real biological fluids to evaluate the effective detection limit and also the selectivity over other competitive anions (e.g. citrate, phosphate, bicarbonate...).

Theoretical calculations suggest that the most likely coordination mode is that involving the hydroxyl group.

The use of $[\mathrm{Tb}(\mathrm{bped})]^{+}$and $[\mathrm{Tb}(\mathrm{rac} \text {-bpcd })]^{+}$complexes as chiroptical luminescent probes of L-lactate underlines the peculiar role of the chiral DACH backbone: the target anion is capable to induce CPL activity from the racemic mixture of $\mathrm{Tb}$ complexes containing DACH-based ligand [Figure 6c, $\left.[\mathrm{Tb}(\mathrm{rac} \text {-bpcd })]^{+}\right]$but not from $[\mathrm{Tb}(\text { bped })]^{+}$complex (Figure $\left.\mathrm{S} 4\right)$. This evidence is connected with the different CPL activity of the two diastereomeric adducts, being $(R, R)$-L less CPL-active than $(S, S)$ L.

Our findings would lend themselves to the development of an analytical assay based on $\mathrm{Tb}$ luminescence in the visible. Moreover, thanks to the differential quantum yield of the two diastereomeric species $(R, R)-\mathrm{L}$ and $(S, S)-\mathrm{L}$, one can use the racemic complex to reveal L-lactate by measuring the induced $C P L$ spectrum. Interestingly this has been demonstrated in a commercial complex solution for medical use, containing several electrolytes, namely Ringer's lactate. The results 
reported here are encouraging, although the light-absorption features of the ligand and consequently the excitation spectrum of the complex are not ideal for practical uses, because they require hard UV excitation. We prospect that by manipulating the pyridine chromophore softer excitation can be obtained.

\section{Supporting information.}

Luminescence decay curves, additional structural and energetic results for [Y(bped)]S-lactate] complexes and CPL titration of $[\mathrm{Tb}(\text { bped })]^{+}$with L-lactate.

\section{Bibliography}

1 S. Azzouzi, L. Rotariu, A. M. Benito, W. K. Maser, M. Ben Ali and C. Bala, Biosens. Bioelectron., 2015, 69, 280-286.

2 R. P. Dellinger, M. M. Levy, A. Rhodes, D. Annane, H. Gerlach, S. M. Opal, J. E. Sevransky, C. L. Sprung, I. S. Douglas, R. Jaeschke, T. M. Osborn, M. E. Nunnally, S. R. Townsend, K. Reinhart, R. M. Kleinpell, D. C. Angus, C. S. Deutschman, F. R. Machado, G. D. Rubenfeld, S. Webb, R. J. Beale, J. L. Vincent, R. Moreno, R. P. Dellinger, R. Moreno, L. Aitken, H. Al Rahma, D. C. Angus, D. Annane, R. J. Beale, G. R. Bernard, P. Biban, J. F. Bion, T. Calandra, J. A. Carcillo, T. P. Clemmer, C. S. Deutschman, J. V. Divatia, I. S. Douglas, B. Du, S. Fujishima, S. Gando, H. Gerlach, C. G. Bruch, G. Guyatt, J. A. Hazelzet, H. Hirasawa, S. M. Hollenberg, J. Jacobi, R. Jaeschke, I. Jenkins, E. Jimenez, A. E. Jones, R. M. Kacmarek, W. Kern, R. M. Kleinpell, S. O. Koh, J. Kotani, M. Levy, F. Machado, J. Marini, J. C. Marshall, H. Masur, S. Mehta, J. Muscedere, L. M. Napolitano, M. E. Nunnally, S. M. Opal, T. M. Osborn, M. M. Parker, J. E. Parrrillo, H. Qiu, A. G. Randolph, K. Reinhart, J. Rello, E. Resende, A. Rhodes, E. P. Rivers, G. D. Rubenfeld, C. A. Schorr, J. E. Sevransky, K. Shukri, E. Silva, M. D. Soth, C. L. Sprung, A. E. Thompson, S. R. Townsend, J. S. Vender, J. L. Vincent, S. A. Webb, T. Welte and J. L. Zimmerman, Intensive Care Med., 2013, 39, 165228.

3 C. Henchcliffe, D. C. Shungu, X. Mao, C. Huang, M. J. Nirenberg, B. G. Jenkins and M. F. Beal, Ann. N. Y. Acad. Sci., 2008, 1147, 206-220. 
A. G. Feldman, R. J. Sokol, R. M. Hardison, E. M. Alonso, R. H. Squires, M. R. Narkewicz and Pediatric Acute Liver Failure Study Group, J. Pediatr., 2017, 182, 217-222.e3. J. M. Lupo, A. P. Chen, M. L. Zierhut, R. A. Bok, C. H. Cunningham, J. Kurhanewicz, D. B. Vigneron and S. J. Nelson, Magn. Reson. Imaging, 2010, 28(2), 153-162. R. Gyawali and S. a Ibrahim, Emirates J. Food Agric., 2012, 24, 1-11. J. Yuasa, T. Ohno, H. Tsumatori, R. Shiba, H. Kamikubo, M. Kataoka, Y. Hasegawa and T. Kawai, Chem. Commun., 2013, 49, 4604.

8 S. Orsini, F. Zinna, T. Biver, L. Di Bari and I. Bonaduce, RSC Adv., 2016, 6, 96176-96181.

9 M. Górecki, F. Zinna, T. Biver and L. Di Bari, J. Pharm. Biomed. Anal., 2017, 144, 6-11.

10 T. aki Uchida, K. Nozaki and M. Iwamura, Chem. - An Asian J., 2016, 11, 2415-2422.

11 G. Muller, Dalt. Trans., 2009, 9692.

12 B. T. Nguyen, A. J. Ingram and G. Muller, Chirality, 2016, 28, 325-331.

13 B. Zercher and T. A. Hopkins, Inorg. Chem., 2016, 55, 10899-10906.

14 E. R. Neil and D. Parker, RSC Adv., 2017, 7, 4531-4540.

15 J. C. G. Bünzli, Chem. Rev., 2010, 110, 2729-2755.

16 A. T. Frawley, R. Pal and D. Parker, Chem. Commun., 2016, 52, 13349-13352.

17 F. Piccinelli, A. Melchior, A. Speghini, M. Monari, M. Tolazzi and M. Bettinelli, Polyhedron, 2013, 57, 30-38.

18 F. Piccinelli, M. Bettinelli, A. Melchior, C. Grazioli and M. Tolazzi, Dalt. Trans., 2015, 44, 182-192.

19 F. Piccinelli, M. Leonzio, M. Bettinelli, A. Melchior, G. Faura and M. Tolazzi, Inorg. Chim. Acta, 2016, 453, 751-756.

20 M. Leonzio, A. Melchior, G. Faura, M. Tolazzi, F. Zinna, L. Di Bari and F. Piccinelli, Inorg. Chem., 2017, 56, 4413-4422.

21 A. C. Mendonça, A. F. Martins, A. Melchior, S. M. Marques, S. Chaves, S. Villette, S. Petoud, P. L. Zanonato, M. Tolazzi, C. S. Bonnet, É. Tóth, P. Di Bernardo, C. F. G. C. Geraldes and M. A. Santos, Dalt. Trans., 2013, 42, 6046.

22 F. Endrizzi, A. Melchior, M. Tolazzi and L. Rao, Dalton Trans., 2015, 44.

23 A. Melchior, C. Gaillard, S. Gràcia Lanas, M. Tolazzi, I. Billard, S. Georg, L. Sarrasin and M. Boltoeva, Inorg. Chem., 2016, 55, 3498-3507.

24 F. Endrizzi, P. Di Bernardo, P. L. Zanonato, F. Tisato, M. Porchia, A. Ahmed Isse, A. Melchior and M. Tolazzi, Dalton Trans., 2017, 46, 1455-1466.

25 C. Comuzzi, P. Polese, A. Melchior, R. Portanova and M. Tolazzi, Talanta, 2003, 59, 67-80.

26 S. Del Piero, A. Melchior, P. Polese, R. Portanova and M. Tolazzi, Ann. Chim., 2006, 96. 
27 M. Soulié, F. Latzko, E. Bourrier, V. Placide, S. J. Butler, R. Pal, J. W. Walton, P. L. Baldeck, B. Le Guennic, C. Andraud, J. M. Zwier, L. Lamarque, D. Parker and O. Maury, Chem. - A Eur. J., 2014, 20, 8636-8646.

28 R. D. Shannon and C. T. Prewitt, Acta Crystallogr. Sect. B Struct. Crystallogr. Cryst. Chem., 1969, 25, 925-946.

29 C. T. Lee, W. T. Yang and R. G. Parr, Phys.Rev.B, 1988, 37, 785-789.

30 A. D. Becke, J.Chem.Phys., 1993, 98, 1372-1377.

31 X. Cao and M. Dolg, J. Chem. Phys., 2001, 115, 7348-7355.

32 P. Di Bernardo, P. L. Zanonato, A. Bismondo, A. Melchior and M. Tolazzi, Dalton Trans., 2009, 4236-4244.

33 J. Tomasi, B. Mennucci and R. Cammi, Chem. Rev., 2005, 105, 2999-3093.

34 M. J. Frisch, G. W. Trucks, H. B. Schlegel, G. E. Scuseria, M. A. Robb, J. R. Cheeseman, G. Scalmani, V. Barone, G. A. Petersson, H. Nakatsuji, X. Li, M. Caricato, A. V Marenich, J. Bloino, B. G. Janesko, R. Gomperts, B. Mennucci, H. P. Hratchian, J. V Ortiz, A. F. Izmaylov, J. L. Sonnenberg, D. Williams-Yung, F. Ding, F. Lipparini, F. Egidi, J. Goings, B. Peng, A. Petrone, T. Henderson, D. Ranasinghe, V. G. Zakrzewski, J. Gao, N. Rega, G. Zheng, W. Liang, M. Hada, M. Ehara, K. Toyota, R. Fukuda, J. Hasegawa, M. Ishida, T. Nakajima, Y. Honda, O. Kitao, H. Nakai, T. Vreven, K. Throssell, J. A. Montgomery Jr., J. E. Peralta, F. Ogliaro, M. Bearpark, J. J. Heyd, E. Brothers, K. N. Kudin, V. N. Staroverov, T. A. Keith, R. Kobayashi, J. Normand, K. Raghavachari, A. Rendell, J. C. Burant, S. S. Iyengar, J. Tomasi, M. Cossi, J. M. Millam, M. Klene, C. Adamo, R. Cammi, J. W. Ochterski, R. L. Martin, K. Morokuma, O. Farkas, J. B. Foresman and D. J. Fox, Gaussian 16 Revis. A 03, 2016.

35 F. Zinna, T. Bruhn, C. A. Guido, J. Ahrens, M. Bröring, L. Di Bari and G. Pescitelli, Chem. A Eur. J., 2016, 22, 16089-16098.

36 J.-C. G. Bünzli and S. V. Eliseeva, "Basics of Lanthanide Photophysics" in "Lanthanide Luminescence Photophysical, Analytical and Biological Aspects" P. Hänninen and H. Härmä (Eds.) Springer, Berlin, Heidelberg, 2010, pp. 1-45.

37 W. D. W. Horrocks and D. R. Sudnick, J. Am. Chem. Soc., 1979, 101, 334-340.

38 R. M. Supkowski and W. D. W. Horrocks, Inorg. Chim. Acta, 2002, 340, 44-48.

39 H. A. Benesi and J. H. Hildebrand, J. Am. Chem. Soc., 1949, 71, 2703-2707.

40 E. Arunkumar, A. Ajayaghosh and J. Daub, J. Am. Chem. Soc., 2005, 127, 3156-3164.

41 P. Di Bernardo, A. Melchior, M. Tolazzi and P. L. Zanonato, Coord. Chem. Rev., 2012, 256, $328-351$.

42 A. Bianchi, L. Calabi, F. Corana, S. Fontana, P. Losi, A. Maiocchi, L. Paleari and B. 
Valtancoli, Coord. Chem. Rev., 2000, 204, 309-393.

43 F. V. H. Deelstra, Anal. Chim. Acta, 1964, 31, 251-257.

44 M. Nilsson and K. L. Nash, Solvent Extr. Ion Exch., 2007, 25, 665-701.

45 A. Barkleit, J. Kretzschmar, S. Tsushima and M. Acker, Dalton Trans., 2014, 43, 11221-32.

46 L. E. Roy and L. R. Martin, Dalt. Trans., 2016, 45, 15517-15522.

47 E. W. J. L. Oomen and A. M. A. van Dongen, J. Non. Cryst. Solids, 1989, 111, 205-213.

48 R. Reisfeld, E. Zigansky and M. Gaft, Mol. Phys., 2004, 102, 1319-1330. 